\title{
Macrophage Phagocytosis and Allergen Avoidance in Children With Asthma
}

\begin{abstract}
Neeta Kulkarni ${ }^{1}$, Ahmad Kantar ${ }^{2 *}$, Silvia Costella ${ }^{3}$, Vincenzo Ragazzo ${ }^{4}$, Giorgio Piacentini ${ }^{5}$, Attilio Boner ${ }^{5}$ and Christopher O'Callaghan ${ }^{6}$
\end{abstract}

\begin{abstract}
'Department of Infection, Immunity and Inflammation, Institute for Lung Health, University of Leicester, Leicester, United Kingdom, ${ }^{2}$ Pediatric Cough and Asthma Center, Istituti Ospedalieri Bergamaschi, University and Research Hospitals, Bergamo, Italy, ${ }^{3}$ High Altitude Paediatric Asthma Centre in Misurina, Pio XII Institute, Belluno, Italy, ${ }^{4}$ Department of Pediatrics, Versilia Hospital, Lido di Camaiore, Italy, ${ }^{5}$ Pediatrics Section, Department of Surgery, Dentistry, Paediatrics, and Gynaecology, University of Verona, Verona, Italy, ${ }^{6}$ Respiratory, Critical Care and Anaesthesia, UCL Great Ormond Street Institute of Child Health, NIHR Great Ormond Street Hospital Biomedical Research Centre, Great Ormond Street Children's Hospital, London, United Kingdom
\end{abstract}

Background and Objective: Airway macrophages perform the crucial functions of presenting antigens, clearing pathogens, and apoptotic cells. Macrophage phagocytosis is increased in adults with mild asthma and allergen exposure is known to activate macrophages. However, it is not clear whether the mechanism behind this is due to a primary defect or environmental factors such as allergen or lipopolysaccaride (LPS)

OPEN ACCESS

Edited by:

Milos Jesenak,

Jessenius Faculty of Medicine,

Comenius University, Slovakia

Reviewed by:

Yusei Ohshima,

University of Fukui, Japan

Giuseppe Pingitore,

Allergy Unit "G.B.Grassi" Hospital,

ASL Roma D, Italy

*Correspondence:

Ahmad Kantar

kantar@centropediatricotosse.com

Specialty section:

This article was submitted to

Pediatric Pulmonology,

a section of the journal

Frontiers in Pediatrics

Received: 21 May 2018

Accepted: 02 July 2018

Published: 02 August 2018

Citation:

Kulkarni N, Kantar A, Costella S, Ragazzo V, Piacentini G, Boner A and

O'Callaghan C (2018) Macrophage

Phagocytosis and Allergen Avoidance

in Children With Asthma.

Front. Pediatr. 6:206.

doi: 10.3389/fped.2018.00206 exposure. Our aim was to assess the phagocytic function of airway macrophages in children with mild to moderate asthma after residence in a low allergen \LPS environment at high altitude.

Methods: Sputum induction was performed in children with asthma at baseline and after residence for a 3 weeks' period at a high-altitude asthma center that has very low ambient allergen levels. The markers of eosinophilic inflammation (including percentage of macrophage cytoplasm with red hue) and phagocytosis of fluorescein isothiocyanatelabeled, heat-killed Staphylococcus aureus by airway macrophages was analyzed. Internalized bacteria were quantified using confocal microscopy.

Results: The median bacterial count [mean (standard deviation)] per macrophage was significantly lower [39.55 (4.51) vs. 73.26 (39.42) $(p=0.006)]$ after residence at high altitude. No association was observed between markers of eosinophilic inflammation and bacterial phagocytosis.

Conclusions: The results suggest that the mechanism behind the enhanced phagocytosis of bacteria in childhood asthma may be secondary to allergen or possibly LPS exposure.

Keywords: macrophages, phagocytosis, asthma, children, allergen avoidance

\section{INTRODUCTION}

In recent years, knowledge of macrophage biology has vastly improved. The normally protective alveolar macrophages can turn into pathogenic cells in adverse lung environment demonstrating their plasticity (1). The transcriptome and epigenetic landscape of tissue macrophages have been demonstrated as being determined by the tissue-specific microenvironment. Macrophages are 
constantly sensing the milieu of the adjacent stroma to regulate the tissue homeostasis both during steady and inflammatory states. (2). Lavin at all have shown that local tissue environment can alter the macrophages to acquire the identity and function of tissue resident macrophages e.g., transfer of bone marrow derived alveolar macrophages or mature peritoneal macrophages into alveolar space converted to alveolar macrophage-like cells (3).

Irrespective of the origin of macrophages (fetal, adult or differentiated tissue) once in lung environment they can fully function as alveolar macrophages and are similar at genomic and epigenomic levels $(4,5)$. Various studies have revealed that the development and resolution of lung injury is accompanied by remarkable changes in the numbers and types of macrophages $(6,7)$.

The lung is exposed to the environmental toxins like, microorganisms, chemical agents (including environmental LPS), allergens, and antigens. The alveolar and airway macrophages perform a dual role of activation and suppression of inflammation (8).

Asthma research has long been focused on cells that appear to be the major contributors of airway inflammation, including eosinophils, neutrophils, and lymphocytes. However, few studies have endorsed the mechanisms of function and regulation of macrophages that may orchestrate the inflammatory process. Macrophages are front line defenders of innate immunity and also play a crucial role in organ development, tissue turnover, and regeneration (9). The macrophages are capable of sensing viral, microbial, parasitic antigens, immune complexes, and apoptotic or necrotic cells which helps in immune surveillance (9-11).

Airway macrophage phagocytosis in adults with mild asthma is increased compared to healthy individuals and is possibly related to higher levels of activation of macrophages (12). The enhanced phagocytic function could be related to increased levels of cysteinyl leukotrienes in allergic lung (13) or other inflammatory mechanisms. However, Alexis et al. (12) observed adults with mild asthma, and those with higher eosinophil counts had lower phagocytosis (12). This suggests that macrophage phagocytic function may be related to an interaction with allergen and eosinophilic inflammation. Thus far, there have been no studies on allergen exposure reduction to test this as a possible cause of enhanced phagocytosis. In addition, LPS is well known to activate macrophages resulting in increased chemotactic and phagocytic activity (14) and therefore reduction of LPS would reduce phagocytic activity.

Because of the low relative humidity at high altitudes, the environment is free of house dust mites and molds (15). A number of studies in children (16-20) and adults with asthma have revealed a beneficial effect of high altitude residence on symptoms, lung function, and eosinophilic inflammation (21). However, no study has explored the effect of high altitude on macrophage phagocytosis, which results in a marked reduction in allergen and also possibly LPS exposure.

In adults with high levels of airway eosinophilic inflammation (defined as a sputum eosinophil count greater than 5\%), macrophage phagocytosis has been shown to be lower, indicating that eosinophilic inflammation may affect phagocytosis (12). The toxic effect of eosinophil proteins on the epithelium and other cells $(22,23)$ is well known. These proteins may impair macrophage function.

We have previously shown, however, that sputum eosinophil count alone may be insufficient to identify ongoing eosinophilia (24). In children with asthma glucocorticoid treatment results in reduction of sputum eosinophil count, this could also be due to drop in recruitment of eosinophils because of natural resolution of disease process. Corticosteroid therapy increases eosinophil apoptosis and uptake by macrophages, thereby increasing the eosinophil protein content within the macrophages. To differentiate between these processes and to identify ongoing eosinophilia, we recently developed a novel marker of eosinophilic inflammation (eosinophil protein content in airway macrophages) (24).

In this study we hypothesized that airway macrophage phagocytosis would be lower after reduction of allergen exposure in children with mild to moderate asthma. To test our hypothesis, we compared airway macrophage phagocytosis before and after allergen avoidance during residence at the High Altitude Paediatric Asthma Centre in Misurina $(1,756 \mathrm{~m})$, which offers residential treatment for children with asthma. In addition, we assessed the relationship between airway macrophage phagocytosis and markers of eosinophilic inflammation (including eosinophilic proteins in airway macrophages) before their high-altitude residence. According to our understanding, this is the first study that explores the effect of a high altitude, with allergen and possibly LPS avoidance, on the phagocytic function of sputum macrophages in pediatric or adult asthma.

\section{MATERIALS AND METHODS}

\section{Study Patients}

The study enrolled children aged $7-17$ years $(n=62)$ admitted to Istituto Pio XII, Misurina, Belluno (High Altitude Paediatric Asthma Centre) from various cities in Italy between June and September 2010. Children with a diagnosis of asthma and residing in the center for 3 weeks or more were included. The diagnosis of asthma was supported by clinical symptoms and reversibility testing ( $>12 \%$ increase in $\mathrm{FEV}_{1}$ after short acting bronchodilator treatment) (25). The exclusion criteria were respiratory infection in the preceding 6 weeks, congenital heart disease and chronic suppurative lung disease, or associated respiratory conditions such as cystic fibrosis and primary ciliary dyskinesia.

\section{Study Design}

On the day of arrival (T0) the demographic data, exposure to tobacco smoke, and medications including the doses of inhaled steroids were recorded. All children underwent clinical examination; spirometry, FeNO, and skin prick tests were performed. Spirometry was carried out as per the American Thoracic Society Guidelines (26). Sputum induction and blood eosinophil blood counts were performed within 2 days of arrival. At the end of the stay (T1) the symptoms during the stay and the treatment received were recorded and sputum induction was performed. The inhaled corticosteroid dose was converted to an estimated equipotent daily dose, in accordance with the 
guidelines of the Global Initiative for Asthma (GINA) (25) to compare the groups. Ethical approval was obtained by the Ethics Committee for Clinical Research of the Local Heath Authority in Belluno, and the parents provided written informed consent for the study. Our investigation was restricted to children with asthma because no healthy children resided at a high altitude for the time required by the study.

\section{METHODS}

\section{Reagents and Chemicals}

All reagents, culture media, and latex beads were purchased from Sigma-Aldrich (Milan, Italy) unless otherwise specified.

\section{EXHALED NITRIC OXIDE MEASUREMENT}

FeNO was measured using a standard technique complying with the recommendations of the European Respiratory Society/American Thoracic Society (27), using a chemiluminescence analyzer (Logan LR 2149; Logan Research Ltd., Rochester, Kent, UK), and expressed as parts per billion (ppb).

\section{SPUTUM INDUCTION AND PROCESSING}

Sputum was induced and processed as described previously (28, 29). Air-dried cytospins were stained with Diff-Quik. The total cell count, cell viability, and level of squamous cell contamination were assessed. The eosinophil differential count was obtained by counting 400 non-squamous cells and expressed as a percentage. The children were divided into 2 groups depending on the differential count on arrival (T0): eosinophilic ( $\geq 3 \%)$ and noneosinophilic $(<3 \%)$.

\section{Macrophage Eosinophil Protein Content}

The image analysis method used was as previously described (24). Please refer to the online supporting information for details.

\section{Macrophage Culture and Phagocytosis Assays}

The macrophage culture and phagocytosis are described in the online supporting information.

\section{CONFOCAL MICROSCOPY AND IMAGE ANALYSIS OF STAPHYLOCOCCUS AUREUS PHAGOCYTOSIS}

After adherence, macrophages were incubated for $2 \mathrm{~h}$ with fluorescein isothiocyanate conjugated, heat-killed Staphylococcus aureus (Invitrogen Milan Italy) resuspended in RPMI 1640 supplemented with 5\% FBS (10:1 ratio of staph aureus/Airway Macrophage). Please refer to online supporting information for details of further processing of sample, confocal microscopy, and image analysis to quantify internalized bacteria. The median bacterial count/airway macrophage and median maximum intensity $\backslash$ airway macrophage was calculated for each subject.

\section{Latex Bead Phagocytosis: Phagocytic Index}

After adherence, macrophages were incubated with $2-\mu \mathrm{m}$ latex beads (airway macrophage: bead $=1: 10$ ) resuspended in RPMI 1640 (supplemented with 5\% FBS) for $2 \mathrm{~h}$. Please refer to the online supporting information for details on the counting of internalized bacteria. The phagocytic index (beads/100 airway macrophages) and number of phagocytic macrophages were calculated.

\section{Statistics}

Statistical analysis was performed using GraphPad Prism 6 (GraphPad, San Diego, CA, USA). Patient characteristics are presented as mean (standard error), median (range or interquartile range) or percentages. The between-group comparisons for non-parametric data were made using the Mann-Whitney test for unpaired data and the Wilcoxon matched-pair test for paired data as appropriate and proportions were assessed using Fisher's exact/chi-square test. Differences were considered significant when $p<0.05$. Linear regression and Spearman's co-relations were used to explore the association between the macrophage eosinophil protein content and phagocytosis.

\section{RESULTS}

\section{Patient Characteristics}

The clinical characteristics of 54 children who produced adequate sputum for cell counts on arrival (T0) are as shown in Table 1. All children were in GINA Groups 1-3 (with 77.7\% of children in GINA Groups 1 and 2) depending on the treatment in the previous 3 months prior to the start of residency. Thirty children had sputum eosinophil counts over $3 \%$ and were therefore assigned to the eosinophilic group, with 24 in the non-eosinophilic group. The median (range) sputum eosinophil content in the eosinophilic group was 12\% (3-52\%). Boys were predominant in the eosinophilic group. No difference was observed in $\mathrm{FEV}_{1}$ between the groups. However, the predicted $\mathrm{FEF}_{25-75} \%$ was lower and blood eosinophil and FeNo content were higher in the eosinophilic phenotype (Table 1).

Fifty children produced adequate sputum samples on both occasions (T0 and T1) for differential counts. No statistical difference was observed in lung function measurements before or after their high-altitude stay in a very low ambient allergen environment. However, after exposure to a high altitude (T1), they had a significantly lower FeNO $(p<0.001)$ and eosinophil counts $(p=0.001$ ) (Table 2 , Figure 1d). No difference was observed in percentage cell viability (Table 1) (all cell types) in the eosinophilic and non-eosinophilic groups or in the T0 or T1 samples. The patients who produced an adequate sample for phagocytosis assay did not differ from those who did in age, lung function parameters, blood eosinophil counts, or sputum cell counts. The equipotent inhaled corticosteroid dose was reduced $(p=0.01)$ (Table 2) during their stay at the center because the children were exhibiting fewer symptoms. 


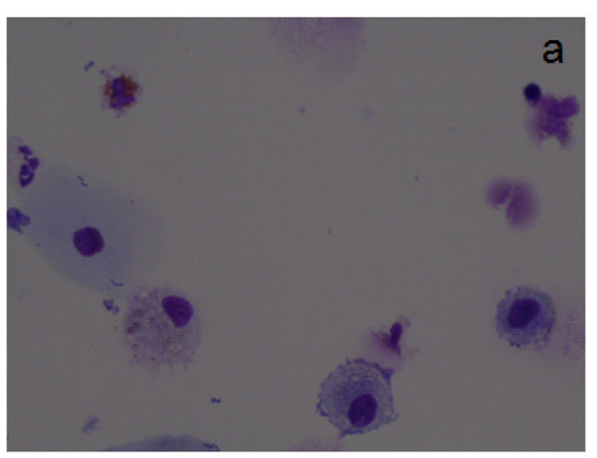

c

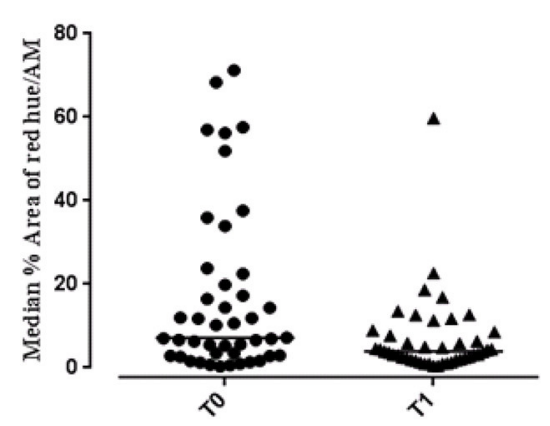

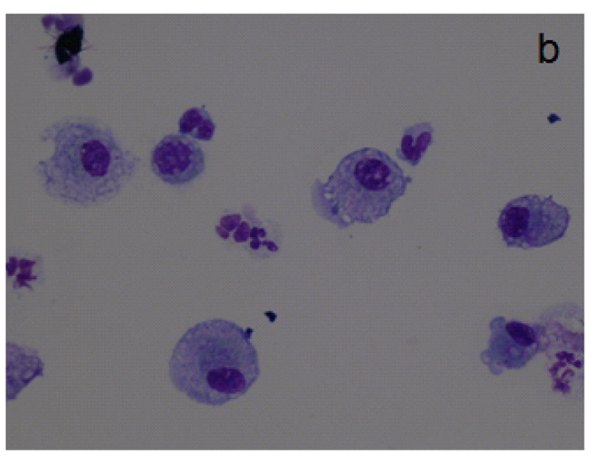

d

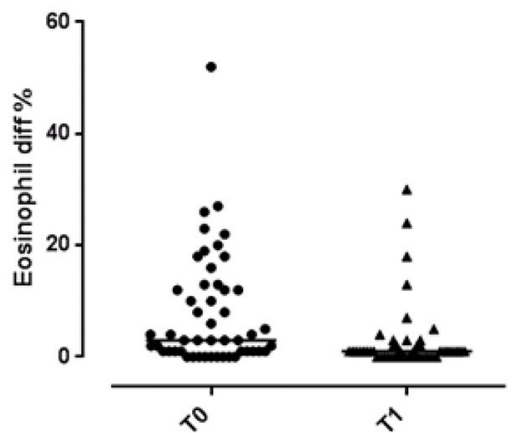

FIGURE 1 | Eosinophilic staining of macrophages at (a) T0 and (b) T1. Graphs showing (c) the median \% red hue/airway macrophage ratio, and (d) sputum eosinophil differential counts at TO and T1.

\section{Macrophage Eosinophilic Proteins}

Example images of red hue in macrophages before and after residence in Misurina, as an index of eosinophil uptake, are shown in Figures 1a,b. No significant difference was observed $(p=0.39)$ between median airway macrophage red hue percentage in eosinophilic $(n=30)$ [median (range)] [5.9 (0.657.6)] and non-eosinophilic asthma $(n=24)$ [8.7 (0.34-71.2)]. After time spent at a high altitude (T1), the children $(n=43$ pairs) had a significantly lower airway macrophage red hue percentage $[p=0.005]$ than before T0 (Table 2, Figure 1c).

\section{Macrophage Phagocytosis}

Examples of confocal images showing internalized bacteria and light microscopy images showing latex beads are presented in Figures 2, 3, respectively. No significant difference $(p=0.3)$ was observed between the median bacterial counts in eosinophilic $(n=16)$ and non-eosinophilic asthma $(n=8)$ at T0. After exposure to a high altitude (T1), the children ( $n=19$ pairs) exhibited significantly lower median bacterial counts [Mean (standard deviation)] [ $p=0.006,39.55$ (4.51) vs. 73.26 (39.42)] than at T0 (Table 3 ).

\section{Eosinophilic Inflammation and Phagocytosis}

No significant correlation or association was observed between age, FeNo, pre- and post-bronchodilator lung function $\left(\mathrm{FEV}_{1} \%\right.$ predicted, $\mathrm{FVC} \%$ predicted, $\mathrm{FEF}_{25-75} \%$ predicted), blood counts (total white count, eosinophil count), or sputum parameters (viability, eosinophil and neutrophil counts) and bacterial uptake by macrophages (median bacterial count) and median maximum intensity (bacterial fluorescence). Latex bead phagocytosis (number of phagocytic macrophages (\%) and phagocytic index) were significantly positively associated with FeNo $(p=0.028)$ and blood eosinophils $(p=0.028)$, but were not associated with any other parameter. There was a positive correlation between number of phagocytic macrophages (\%) and blood eosinophils $(r=0.508, p=0.046)$. The median airway macrophage red hue area percentage was not associated with bacterial or latex phagocytosis parameters. Please refer to online Supplement Figures 1-4.

\section{DISCUSSION}

Alveolar macrophages line the luminal surface and are primary defense mechanism to protect the lungs from invading pathogens and pollutants. They initiate and evolve the immune response in the lung. Overall, the number of macrophages in patients with asthma is similar to that in healthy individuals (30).

In asthma, two major functionally distinct subsets of macrophages have been intensively investigated: the M1 and M2 macrophages. Macrophages have been grouped into M1 and M2 types depending on their function in subjects with asthma. M1 macrophages are differentiated by bacteria-derived mediators such as interferon-c and lipopolysaccaride (LPS) 

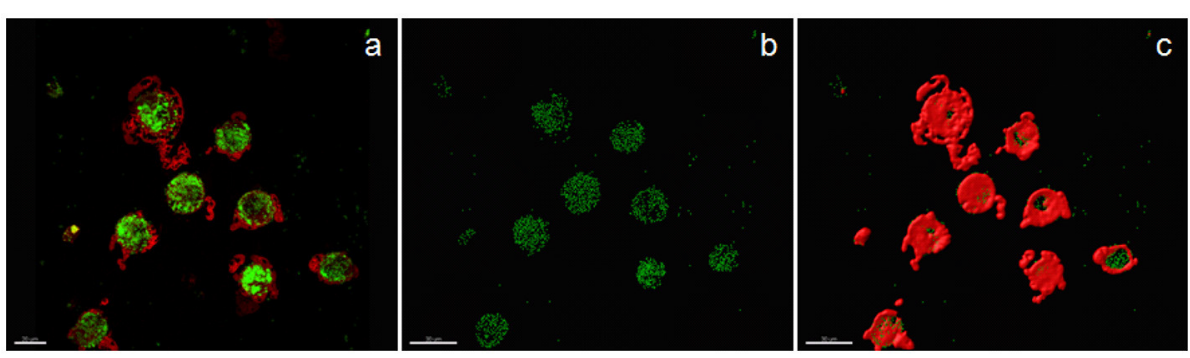

FIGURE 2 | Confocal image of sputum macrophages cultured with heat-killed fluorescein isothiocyanate-labeled Staphylococci aureus (airway macrophage:bacteria = 1:10) showing internalized bacteria. (a) Confocal image of bacteria (green) and cytoplasm (red), (b) bacteria alone, and (c) the surface view of macrophages showing that a majority of the bacteria are internalized.

TABLE 1 | Baseline characteristics of patients.

\begin{tabular}{|c|c|c|c|}
\hline & $\begin{array}{l}\text { Eosinophilic } \\
\text { group } \\
(n=30)\end{array}$ & $\begin{array}{l}\text { Non-eosinophilic } \\
\text { group } \\
(n=24)\end{array}$ & $p$-value \\
\hline Mean age (yr) (SD) & $13.51( \pm 3.1)$ & $13.02( \pm 2.9)$ & 0.55 \\
\hline Sex (male), No. (\%) & $25(83.3)$ & $13(54.1)$ & 0.034 \\
\hline $\mathrm{BMl}$ & 18.99 (14.4-31.9) & $19.99(12.8-41.1)$ & 0.7 \\
\hline $\begin{array}{l}\text { Smoking in house (yes) No. } \\
\text { (\%) }\end{array}$ & $12(40)$ & 7 (29.2) & 0.56 \\
\hline Food allergy (yes) No. (\%) & $14(46.6)$ & $9(37.5)$ & 0.58 \\
\hline GINA Classification No. (\%) & & & 0.30 \\
\hline 1 & $6(20)$ & $9(37.5)$ & \\
\hline 2 & $17(56.7)$ & $10(41.7)$ & \\
\hline 3 & 7 (23.3) & $4(16.7)$ & \\
\hline 5 & 0 & $1(4.1)$ & \\
\hline $\begin{array}{l}\mathrm{FEV}_{1} \% \text { predicted mean } \\
\text { (SE) }\end{array}$ & $106.8(2.97)$ & $113.7(3.7)$ & 0.13 \\
\hline FVC\% predicted mean (SE) & $104.5(2.22)$ & $107.2(2.8)$ & 0.45 \\
\hline $\begin{array}{l}\mathrm{FEF}_{25}-75 \% \text { predicted Mean } \\
\text { (SE) }\end{array}$ & $98.27(5.03)$ & $115.9(6.5)$ & 0.034 \\
\hline Blood eosinophils (\%) & $7.8(3.9-12.1)$ & $5.05(1.9-13.1)$ & 0.014 \\
\hline Median FeNo (ppb) (range) & 23.75 (6.3-79.3) & $12.8(12.7-41.1)$ & 0.001 \\
\hline \multicolumn{4}{|c|}{ MEDIAN INDUCED SPUTUM (RANGE) } \\
\hline $\begin{array}{l}\text { Total cell count } \times 10^{6} \backslash \mathrm{g} \\
\text { sputum }\end{array}$ & $2.3(0.39-9.5)$ & $1.7(0.05-7.2)$ & 0.48 \\
\hline Cell viability (\%) & $86.5(59.7-96.4)$ & $88.9(57.9-100)$ & 0.27 \\
\hline Macrophages (\%) & $62.5(1-88)$ & $72.5(14-97)$ & 0.17 \\
\hline Neutrophils (\%) & $22(8-72)$ & 26.5 (3-86) & 0.46 \\
\hline
\end{tabular}

(Eosinophilic group $\geq 3 \%$ sputum eosinophil differential count). Bold P-values indicates $p$ $<0.05$.

and release various inflammatory cytokines and chemokines, whereas M2 macrophages have increased phagocytic activity but are poor at clearing intracellular pathogens. Moreover, experimental data suggests both M1 and M2 subsets are involved in asthma (31). In addition there are regulatory macrophages performing different physiological functions and develop in response to different stimuli (32). These are vital in regulating immune responses and reduce inflammation (33). Macrophages are critical for both innate and acquired immunity and play
TABLE 2 | Lung function, FeNo, sputum differential counts, inhaled corticosteroids, and macrophage red hue percentage results on arrival (TO), and after the allergen reduction intervention (3-week residence at a high-altitude asthma center) (T1).

\begin{tabular}{|c|c|c|c|}
\hline & $\begin{array}{c}\text { T0 } \\
(n=50)\end{array}$ & $\begin{array}{c}\text { T1 } \\
(n=50)\end{array}$ & $\begin{array}{c}p- \\
\text { value }\end{array}$ \\
\hline $\mathrm{FEV}_{1} \%$ predicted mean (SE) & $109.5(2.4)$ & $116.0(2.04)$ & 0.67 \\
\hline FVC\% predicted mean (SE) & $105.8(1.81)$ & $105.6(1.89)$ & 0.91 \\
\hline $\begin{array}{l}\text { FEV/FVC ratio \% predicted } \\
\text { mean (SE) }\end{array}$ & $103.1(1.29)$ & $101.8(1.3)$ & 0.56 \\
\hline $\begin{array}{l}\text { FEF }_{25}-75 \% \text { predicted mean } \\
\text { (SE) }\end{array}$ & $105.3(4.38)$ & $102.9(4.01)$ & 0.72 \\
\hline Median FeNo (ppb) (range) & $18.85(2.6-79.3)$ & $11.5(2.1-52.2)$ & 0.0004 \\
\hline ICS treatment* & & & 0.01 \\
\hline No ICS treatment No. (\%) & $13(26)$ & $20(40)$ & \\
\hline Low daily dose No. (\%) & $21(42)$ & $26(52)$ & \\
\hline Medium daily dose No. (\%) & $16(32)$ & $4(8)$ & \\
\hline \multicolumn{4}{|c|}{ MEDIAN INDUCED SPUTUM (RANGE) } \\
\hline $\begin{array}{l}\text { Total cell count } \times 10^{6} \backslash \mathrm{g} \\
\text { sputum }\end{array}$ & $2.2(05-9.5)$ & $2.25(0.26-11.2)$ & 0.24 \\
\hline Macrophages (\%) & $65(1-97)$ & $63(6-87)$ & 0.15 \\
\hline Neutrophils (\%) & $24.5(3-86)$ & $32.5(11-90)$ & 0.006 \\
\hline Eosinophils (\%) & $3(0-52)$ & $1(0-30)$ & 0.001 \\
\hline Lymphocytes (\%) & $0(0-2)$ & $0(0-8)$ & 0.7 \\
\hline $\begin{array}{l}\text { Median \% area red } \\
\text { hue/airway macrophage } \\
\text { (range) ( } n=43 \text { pairs) }\end{array}$ & 7.04 (0.72-71.23) & $3.82(0.41-59.82)$ & 0.005 \\
\hline
\end{tabular}

*GINA classification of equipotent daily dose of inhaled glucocorticosteroids for children older than 5 years (25). Bold P-values indicates $p<0.05$.

a pivotal role in lung defense. Lung macrophages recognize a wide variety of pathogenic antigens, immune complexes, and apoptotic or necrotic cells (11). Increased infection in asthma has led to increased investigation of the clearance of bacterial, cellular, and inhaled particles by macrophages in patients with asthma.

Alexis et al. have demonstrated that phagocytosis of opsonised particles in subjects with mild asthma with airway eosinophilia was lower as compared to those without eosinophilia. Overall phagocytosis was comparable between controls and those with mild intermittent asthma (12). In a similar subjects, phagocytic 


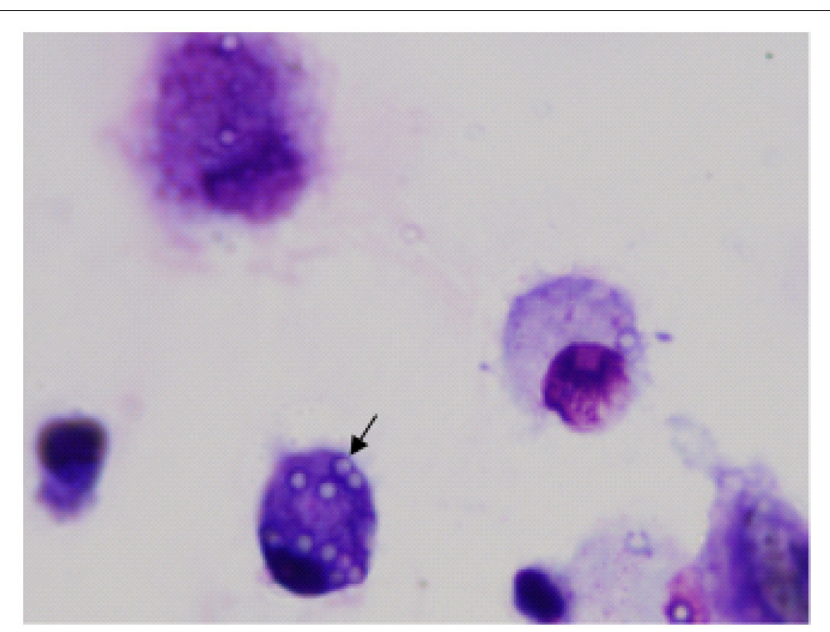

FIGURE 3 | Image of airway macrophages cultured with latex beads (airway macrophage: bead $=1: 10$ ) for $2 \mathrm{~h}$. External beads were digested with xylene. Internalized beads are preserved (arrow).

activity in airway macrophages decreased by about $50 \% 6 \mathrm{~h}$ after endotoxin (LPS) inhalation (34).

Fitzpatrick et al. sampled bronchoalveolar lavage macrophages from children with severe asthma and demonstrated impaired phagocytosis of S. Aureus. Interestingly this remained unchanged after LPS stimulation. Moreover, they have shown that children with severe asthma also had increased alveolar macrophage apoptosis (35). These later findings were attributed to imbalance in glutathione homeostasis (36). Similar findings of reduced phagocytosis of $H$ influenzae and $S$ aureus were seen in bronchoalveolar lavage and monocytederived macrophages from adults with severe asthma (37). Not only bacterial uptake but apoptotic cell clearance by lavage macrophages is reduced in severe asthma as compared to healthy controls or mild-moderate asthma patients (38).

Studies have demonstrated that severe asthma is associated with inflammatory mediators such as prostaglandin E2 and D2, which can suppress the phagocytic activity of alveolar macrophages (39-41). Recently, Brugha et al. investigated the phagocytosis of inhalable carbonaceous particle matter by airway macrophages obtained from the induced sputum of asthmatic children. Their results demonstrated a 51\% lower carbon content in the macrophages of children with moderate to severe asthma compared with mild asthma and healthy children (42). Moreover, the study demonstrated an inverse association between alveolar macrophage carbon and urinary metabolites of prostaglandin E2 and prostaglandin D2.

The effect of a high altitude on improvement of asthma symptoms has been attributed to the very low levels of ambient allergens. In this study, we described for the first time the effect of residence at a high altitude with markedly reduced allergens and possibly pollutants (e.g., LPS) on the phagocytic function of sputum macrophages and markers of eosinophilic inflammation in children with mild to moderate asthma. According to our understanding, this is the original study exploring the effect
TABLE 3 | Phagocytosis assay on arrival (TO) and after the allergen reduction intervention (T1) (3-week residence at a high-altitude asthma center).

\begin{tabular}{lccc}
\hline $\begin{array}{l}\text { Bacterial } \\
\text { phagocytosis } \\
(\boldsymbol{n}=\mathbf{1 9} \text { pairs) }\end{array}$ & T0 & T1 & $\boldsymbol{p}$ \\
\hline Mean bacterial count mea (SD) & $73.26(39.42)$ & $39.55(4.51)$ & $\mathbf{0 . 0 0 6}$ \\
Mean max intensity (SD) & $0.044(0.010)$ & $0.038(0.01)$ & 0.08 \\
LATEX BEAD PHAGOCYTOSIS ( $\mathbf{n = 1 0}$ pairs) & & \\
Median beads/100 cells (range) & $201.0(71.56-1268)$ & $44.52(9.8-246.8)$ & $\mathbf{0 . 0 0 3}$ \\
Mean \% phagocytic AM (SD) & $57.70(16.24)$ & $27.86(16.36)$ & $\mathbf{0 . 0 0 1}$ \\
\hline
\end{tabular}

Bold P-values indicates $p<0.05$.

of reduced allergen $\backslash$ LPS exposure on the phagocytic function of sputum macrophages in pediatric or adult asthma. The phagocytosis of heat-killed bacteria in this group of children decreased after residence at a high altitude and was similar in eosinophilic and non-eosinophilic phenotypes. We also found that bacterial phagocytosis was not associated with parameters of eosinophilic inflammation, including the median airway macrophage red hue percentage.

Our study strongly suggests that allergen and possibly LPS exposure is a major contributor to enhanced macrophage phagocytosis in asthma. The induced sputum macrophage capacity to phagocytose particles has been demonstrated to be higher in subjects with mild asthma $(12,43)$ than in healthy controls. One possible explanation is that activation of macrophages is enhanced in asthma. Silva et al showed that cysteinyl leukotrienes enhanced Fc $\gamma$-mediated phagocytosis in sensitized rats (13). (author?) (28) showed that children with asthma, after residence in a very low ambient allergen environment at a high altitude had lower exhaled breath cysteinyl leukotrienes and leukotriene B4 (28). This might partially explain our finding of reduced phagocytosis in children with mild asthma staying in similar conditions. Along with reduction in allergens there is also possibility of lower level of ambient pollution including LPS. LPS is known to stimulate macrophages and therefore reduction would lower phagocytic capacity.

Fitzpatrick et al. sampled bronchoalveolar lavage macrophages from children with severe asthma and demonstrated impaired phagocytosis (35) but did not include children with mild asthma. We were unable to compare our results of phagocytosis assays with other studies assessing sputum macrophage phagocytosis because this is the first such study on children with asthma. In addition, no studies have included reduction of allergens as an intervention to assess phagocytosis of sputum macrophages. No difference was observed in the viability of sputum cells on arrival or after residence at a high altitude that could have affected the macrophage phagocytic function.

We recently described a novel marker (macrophage eosinophil protein content measured as red hue percentage) that identifies ongoing sputum eosinophilia in patients with asthma and a normal sputum eosinophil count (24). On admission, children without sputum eosinophilia had similar airway macrophage red hue percentages as those with sputum eosinophilia. This suggests the presence of ongoing eosinophilia in the non-eosinophilic group. Because airway macrophages 
acquire eosinophilic proteins by phagocytizing apoptotic eosinophils, a lower airway macrophage red hue suggests that macrophages have ingested fewer eosinophils. Therefore, the combination of low airway macrophage red hue and low sputum eosinophil counts suggests a reduction of eosinophil recruitment to the airways. The reduction of sputum eosinophilia after residence at a high altitude has previously been demonstrated $(20,28)$. In children with asthma glucocorticoid treatment results in reduction of sputum eosinophil count, this could also be due to drop in recruitment of eosinophils because of natural resolution of disease process. Corticosteroid therapy increases eosinophil apoptosis and uptake by macrophages, thus increasing the eosinophil protein content within macrophages. It could be argued that when admitted to the center that supervises administration of treatment, the improved adherence to therapy could have contributed to the reduction in eosinophilic inflammation. However, this is unlikely because the airway macrophage red hue percentage dropped after residence at a high altitude, suggesting reduction of eosinophil ingestion by sputum macrophages and reduced recruitment. Therefore, using the macrophage red hue measurement has the added value of helping to differentiate between a reduced sputum eosinophil count related to treatment and that related to reduced recruitment of eosinophils.

Although evidence (12) indicates that increased eosinophilic inflammation is inversely associated with phagocytosis, we did not find an association between bacterial phagocytosis and markers of eosinophilic inflammation (including the eosinophilic proteins in airway macrophages). However, this relationship must be explored further in children with severe asthma who have persistent inflammation.

Our study had some limitations. We were unable to recruit healthy children because they did not reside for 4 weeks at the high-altitude asthma center. Because of the small amount of sputum samples obtained from the children, insufficient numbers of macrophages were obtained to analyze the macrophages for cell surface markers of activation. It is possible that in vivo

\section{REFERENCES}

1. Joshi N, Walter JM, Misharin AV. Alveolar macrophages. Cell Immunol. (2018). doi: 10.1016/j.cellimm.2018.01.005. [Epub ahead of print].

2. Lavin Y, Mortha A, Rahman A, Merad M. Regulation of macrophage development and function in peripheral tissues Nat Rev Immunol. (2015) 15:731-44. doi: 10.1038/nri3920

3. Lavin Y, Winter D, Blecher-Gonen R, David E, Keren-Shaul H, Merad M, et al. Tissue-resident macrophage enhancer landscapes are shaped by the local microenvironment. Cell (2014) 159:1312-26. doi: 10.1016/j.cell.2014. 11.018

4. Janssen WJ, Barthel L, Muldrow A, Oberley-Deegan RE, Kearns MT, Jakubzick $\mathrm{C}$, et al. Fas determines differential fates of resident and recruited macrophages during resolution of acute lung injury. Am J Respir Crit Care Med. (2011) 184:547-60. doi: 10.1164/rccm.201011-1891OC

5. van de Laar L, Saelens W, De Prijck S, Martens L, Scott CL, Van Isterdael $\mathrm{G}$, et al. Yolk sac macrophages, fetal liver, and adult monocytes can colonize an empty niche and develop into functional tissue-resident macrophages. Immunity (2016) 44:755-68. doi: 10.1016/j.immuni.2016. 02.017 phagocytosis may be affected by other factors that we did not measure. However, our study results indicating higher phagocytosis in patients with mild asthma are like those of inhaled particles in adults in in vivo experiments (43).

In conclusion, induced sputum was successfully used to study macrophage phagocytosis in children with asthma. The sputum macrophages in children with mild to moderate asthma after allergen and possibly lipopolysaccaride avoidance at a high altitude are less phagocytic. Because activation of macrophages by allergens in mild asthma enhances phagocytosis, removal of this stimulus appears to reduce phagocytosis. No association was observed between phagocytosis and eosinophilic inflammation markers. Further research is essential to dissect the mechanism of various types of alveolar macrophage phagocytosis in asthma.

\section{AUTHOR CONTRIBUTIONS}

All authors listed have made a substantial, direct and intellectual contribution to the work, and approved it for publication.

\section{ACKNOWLEDGMENTS}

The authors thank all staff at High Altitude Children's Asthma Center in Misurina, Claire Smith, Louise Donnelly (Imperial College London for advice on methodology), Will Monteiro (Institute for Lung Health in Glenfield Hospital). This research is supported by the NIHR GOSH BRC. The views expressed are those of the author(s) and not necessarily those of the NHS, the NIHR or the Department of Health. NK is the recipient of a European Respiratory Society Fellowship (Number 774).

\section{SUPPLEMENTARY MATERIAL}

The Supplementary Material for this article can be found online at: https://www.frontiersin.org/articles/10.3389/fped. 2018.00206/full\#supplementary-material
6. Alber A, Howie SE, Wallace WA, Hirani N. The role of macrophages in healing the wounded lung. Int J Exp Pathol. (2012) 93:243-51. doi: 10.1111/j.1365-2613.2012.00833.x

7. Misharin AV, Scott Budinger GR, Perlman H. The lung macrophage: a Jack of all trades. Am J Respir Crit Care Med. (2011) 184:497-8. doi: 10.1164/rccm.201107-1343ED

8. Pappas K, Papaioannou AI, Kostikas K, Tzanakis N. The role of macrophages in obstructive airways disease: chronic obstructive pulmonary disease and asthma. Cytokine (2013) 64:613-25. doi: 10.1016/j.cyto.2013. 09.010

9. Akira S, Misawa T, Satoh T, Saitoh T. Macrophages control innate inflammation. Diabetes Obesity Metab. (2013) 15(Suppl. 3):10-8. doi: $10.1111 /$ dom.12151

10. Forbes SJ, Rosenthal N. Preparing the ground for tissue regeneration: from mechanism to therapy. Nat Med. (2014) 20:857-69. doi: 10.1038/nm.3653

11. Roszer T. Understanding the mysterious M2 macrophage through activation markers and effector mechanisms. mediators of inflammation. (2015) 2015:816460. doi: 10.1155/2015/816460

12. Alexis NE, Soukup J, Nierkens S, Becker S. Association between airway hyperreactivity and bronchial macrophage dysfunction in individuals with 
mild asthma. Am J Physiol Lung Cell Mol Physiol. (2001) 280:L369-75. doi: 10.1152/ajplung.2001.280.2.L369

13. Silva RC, Landgraf MA, Hiyane MI, Pacheco-Silva A, Camara NO, Landgraf RG. Leukotrienes produced in allergic lung inflammation activate alveolar macrophages. Cell Physiol Biochem. (2010) 26:319-26. doi: 10.1159/000320555

14. Wu T-T, Chen T-L, Chen R-M. Lipopolysaccharide triggers macrophage activation of inflammatory cytokine expression, chemotaxis, phagocytosis, and oxidative ability via a toll-like receptor 4-dependent pathway: validated by RNA interference. Toxicol. Lett. (2009) 191:195-202. doi: 10.1016/j.toxlet.2009.08.025

15. Spieksma FT, Zuidema P, Leupen MJ. High altitude and house-dust mites. $\mathrm{Br}$ Med J. (1971) 1:82-4.

16. Boner AL, Niero E, Antolini I, Valletta EA, Gaburro D. Pulmonary function and bronchial hyperreactivity in asthmatic children with house dust mite allergy during prolonged stay in the Italian Alps (Misurina, $1756 \mathrm{~m}$ ). Ann. Allergy (1985) 54:42-5.

17. Grootendorst DC, Dahlen SE, Van Den Bos JW, Duiverman EJ, VeselicCharvat M, Vrijlandt EJ, et al. Benefits of high altitude allergen avoidance in atopic adolescents with moderate to severe asthma, over and above treatment with high dose inhaled steroids. Clin Exp Allergy (2001) 31:400-8. doi: 10.1046/j.1365-2222.2001.01022.x

18. Peroni DG, Piacentini GL, Costella S, Pietrobelli A, Bodini A, Loiacono A, et al. Mite avoidance can reduce air trapping and airway inflammation in allergic asthmatic children. Clin Exp Allergy (2002) 32:850-5. doi: 10.1046/j.1365-2222.2002.01372.x

19. Peroni DG, Piacentini GL, Vicentini L, Costella S, Pietrobelli A, Boner AL. Effective allergen avoidance reduces residual volume and sputum eosinophils in children with asthma. J Allergy Clin Immunol. (2001) 108:308. doi: 10.1067/mai.2001.117174

20. Piacentini GL, Del Giudice MJ, Bodini A, Costella S, Vicentini L, Peroni D, et al. Exhaled NO reduced on allergen avoidance. Allergy (2001) 56:251-2. doi: 10.1034/j.1398-9995.2001.056003251.x

21. Rijssenbeek-Nouwens LH, Bel EH. High-altitude treatment: a therapeutic option for patients with severe, refractory asthma? Clin Exp Allergy (2011) 41:775-82. doi: 10.1111/j.1365-2222.2011.03733.x

22. Frigas E, Motojima S, Gleich GJ. The eosinophilic injury to the mucosa of the airways in the pathogenesis of bronchial asthma. Eur Respir J. (1991) $13: 123 s-35 s$.

23. Maeda T, Kitazoe M, Tada H, de Llorens R, Salomon DS, Ueda M, et al. Growth inhibition of mammalian cells by eosinophil cationic protein. Eur $J$ Biochem. (2002) 269:307-16. doi: 10.1046/j.0014-2956.2001.02653.x

24. Kulkarni NS, Hollins F, Sutcliffe A, Saunders R, Shah S, Siddiqui S, et al. Eosinophil protein in airway macrophages: a novel biomarker of eosinophilic inflammation in patients with asthma. J Allergy Clin Immunol. (2010) 126:619 e3. doi: 10.1016/j.jaci.2010.03.026

25. GINA. Gobal Strategy for Asthma Management and Prevention. Global Initiative for Asthma (GINA); Available online at www.ginasthma.org (Accessed March 3, 2014). (2009).

26. ATS. Standardization of Spirometry, 1994 Update. American Thoracic Society. Am J Respir Crit Care Med. (1995) 152:1107-36.

27. American Thoracic Society, European Respiratory Society. ATS/ERS recommendations for standardized procedures for the online and offline measurement of exhaled lower respiratory nitric oxide and nasal nitric oxide, 2005. Am J Respir Crit Care Med. (2005) 171:912-30. doi: 10.1164/rccm.200406-710ST

28. Bodini A, Peroni D, Vicentini L, Loiacono A, Baraldi E, Ghiro L, et al. Exhaled breath condensate eicosanoids and sputum eosinophils in asthmatic children: a pilot study. Pediatr Allergy Immunol. (2004) 15:26-31. doi: 10.1046/j.0905-6157.2003.00097.x

29. Brightling CE, Ward R, Woltmann G, Bradding P, Sheller JR, Dworski R, et al. Induced sputum inflammatory mediator concentrations in eosinophilic bronchitis and asthma. Am J Respir Crit Care Med. (2000) 162(3 Pt 1):878-82. doi: 10.1164/ajrccm.162.3.9909064

30. Donnelly LE, Barnes PJ. Defective phagocytosis in airways disease. Chest (2012) 141:1055-62. doi: 10.1378/chest.11-2348

31. Moreira AP, Hogaboam CM. Macrophages in aller7gic asthma: fine-tuning their pro- and anti-inflammatory actions for disease resolution. J Interf Cytokine Res. (2011) 31:485-91. doi: 10.1089/jir.2011.0027

32. Fleming BD, Mosser DM. Regulatory macrophages: setting the threshold for therapy. Eur J Immunol. (2011) 41:2498-502. doi: 10.1002/eji.201141717

33. Yang M, Kumar RK, Hansbro PM, Foster PS. Emerging roles of pulmonary macrophages in driving the development of severe asthma. J Leukocyte Biol. (2012) 91:557-69. doi: 10.1189/jlb.0711357

34. Alexis NE, Eldridge MW, Peden DB. Effect of inhaled endotoxin on airway and circulating inflammatory cell phagocytosis and CD11b expression in atopic asthmatic subjects. J Allergy Clin Immunol. (2003) 112:353-61. doi: 10.1067/mai.2003.1651

35. Fitzpatrick AM, Holguin F, Teague WG, Brown LA. Alveolar macrophage phagocytosis is impaired in children with poorly controlled asthma. J Allergy Clin Immunol. (2008) 121:1372-8.e1-3. doi: 10.1016/j.jaci.2008.03.008

36. Fitzpatrick AM, Teague WG, Burwell L, Brown MS, Brown LA. Program NNSAR. Glutathione oxidation is associated with airway macrophage functional impairment in children with severe asthma. Pediatr Res. (2011) 69:154-9. doi: 10.1203/PDR.0b013e3182026370

37. Liang Z, Zhang Q, Thomas CM, Chana KK, Gibeon D, Barnes PJ, et al. Impaired macrophage phagocytosis of bacteria in severe asthma. Respiratory Res. (2014) 15:72. doi: 10.1186/1465-9921-15-72

38. Huynh ML, Malcolm KC, Kotaru C, Tilstra JA, Westcott JY, Fadok VA, et al. Defective apoptotic cell phagocytosis attenuates prostaglandin E2 and 15hydroxyeicosatetraenoic acid in severe asthma alveolar macrophages. Am J Respir Crit Care Med. (2005) 172:972-9. doi: 10.1164/rccm.200501-035OC

39. Aggarwal S, Moodley YP, Thompson PJ, Misso NL. Prostaglandin E2 and cysteinyl leukotriene concentrations in sputum: association with asthma severity and eosinophilic inflammation. Clin Exp Allergy (2010) 40:85-93. doi: 10.1111/j.1365-2222.2009.03386

40. Aronoff DM, Canetti C, Peters-Golden M. Prostaglandin E2 inhibits alveolar macrophage phagocytosis through an E-prostanoid 2 receptormediated increase in intracellular cyclic AMP. J Immunol. (2004) 173:559-65. doi: 10.4049/jimmunol.173.1.559

41. Profita M, Sala A, Bonanno A, Riccobono L, Siena L, Melis MR, et al. Increased prostaglandin E2 concentrations and cyclooxygenase-2 expression in asthmatic subjects with sputum eosinophilia. J Allergy Clin Immunol. (2003)112:709-16. doi: 10.1016/S0091

42. Brugha RE, Mushtaq N, Round T, Gadhvi DH, Dundas I, Gaillard E, et al Carbon in airway macrophages from children with asthma. Thorax (2014) 69:654-9. doi: 10.1136/thoraxjnl-2013-204734

43. Lay JC, Alexis NE, Zeman KL, Peden DB, Bennett WD. In vivo uptake of inhaled particles by airway phagocytes is enhanced in patients with mild asthma compared with normal volunteers. Thorax (2009) 64:313-20. doi: $10.1136 /$ thx.2008.096222

Conflict of Interest Statement: The authors declare that the research was conducted in the absence of any commercial or financial relationships that could be construed as a potential conflict of interest.

Copyright (c) 2018 Kulkarni, Kantar, Costella, Ragazzo, Piacentini, Boner and O'Callaghan. This is an open-access article distributed under the terms of the Creative Commons Attribution License (CC BY). The use, distribution or reproduction in other forums is permitted, provided the original author(s) and the copyright owner(s) are credited and that the original publication in this journal is cited, in accordance with accepted academic practice. No use, distribution or reproduction is permitted which does not comply with these terms. 